\title{
Assessment of depression, anxiety and stress among first year MBBS students of a public medical college, Bangladesh
}

\author{
SM Abu Hena Mostafa Alim, ${ }^{1}$ Md Golam Rabbani, ${ }^{2}$ Enayet Karim, ${ }^{3}$ Mohammad Syedul Islam Mullick, ${ }^{4}$ Abdullah Al- \\ Mamun, ${ }^{5}$ Fariduzzaman, ${ }^{6}$ Muhammad Zillur Rahman Khan ${ }^{7}$ \\ ${ }^{1}$ Assistant Professor, Department of Psychiatry, Rajshahi Medical College, Rajshahi, Bangladesh; ${ }^{2}$ Professor, Department of \\ Psychiatry, Popular Medical College, Dhaka, Bangladesh; ${ }^{3}$ Professor, Department of Psychiatry, Somorita Medical College, \\ Dhaka, Bangladesh; ${ }^{4}$ Professor, Department of Child and Adolescent Psychiatry, Bangabandhu Sheikh Mujib Medical University, \\ Dhaka, Bangladesh; ${ }^{5}$ Professor, Department of Psychiatry, Dhaka Medical College, Dhaka, Bangladesh; ${ }^{6}$ Assistant Professor, \\ Department of Psychiatry, Khulna Medical College, Khulna, Bangladesh; ${ }^{7}$ Assistant Professor, Department of Child and Adolescent \\ Psychiatry, National Institute of Mental Health, Sher-E-Bangla Nagar, Dhaka, Bangladesh.
}

Article info

Received : 01 Jan. 2017

Accepted : 29 Feb. 2017

Number of tables : 04

Number of figures : 03

Number of refs : 42

\begin{abstract}
Summary
Medical students confront significant academic, psychosocial and existential stressors for coping with new college and schedule,. So assessment of the symptoms of depression, anxiety and stress among medical students are essential to take necessary steps to treat or prevent any psychiatric morbidity. The objective of the study was to assess depression, anxiety and stress among the first year MBBS students. This was a cross sectional and descriptive study conducted in Khulna Medical College, Bangladesh from December 2009 to July 2010. For this purpose, 105 students fulfilling inclusion and exclusion criteria were taken as sample. They filled up personal data and the short-form Bangla version of DASS (DASS-21 BV) scale. The results showed that, the mean age of students was 18.8 years with male predominance $(54.3 \%)$. Symptoms of depression, anxiety and stress were found among $54.3 \%, 64.8 \%$ and $59.0 \%$ of students respectively. Eighty five (81\%) students either had depression, anxiety or stress alone or in combination. Combination of depression, anxiety and stress was highest (36.2\%). No significant association was found between gender difference and depression, anxiety or stress. Age was positively correlated with depression $(p=0.004)$ and stress $(p=0.001)$. Percentage of 1 st year MBBS students suffering from depression, anxiety and stress were very high. Adequate psychiatric services should be provided to manage these symptoms among medical students.
\end{abstract}

Bang J Psychiatry 2015;29(1):23-29

\section{Introduction}

Like all young adults, undergraduate medical students need to cope with the academic and social demands in their preparation for professional careers as well as psychosocial and psychological changes which are connected to the development of an autonomous personal life. During the tough journey of becoming a physician, various hassles can make them feel depressed, anxious or stressed. One study showed medical school was the number one source of stress for $57 \%$ students. $^{1}$ According to authors, the nature and requirements of medical training and practice are inherently stressful and that stress cannot be eliminated. ${ }^{2}$ Medical schools are responsible for ensuring that graduates are knowledgeable, skillful, and professional. ${ }^{3,4}$ To achieve these goals, medical schools typically use a curriculum of didactic lectures, modeling, supervised practice, mentoring and hands-on experience to augment individual study. ${ }^{5}$ So, medical students coping with a new college and new schedule can easily feel overextended. They confront significant academic, psychological and existential stressors throughout their training. According to research, symptoms of anxiety and symptoms of depression were prevalent in medical students ( $43 \%$ and $14 \%$, respectively). ${ }^{6}$ It was found that stress during education can lead to mental distress and have a negative impact on cognitive functioning and learning. ${ }^{7}$ It may affect the overall performance of both personal and professional levels. Stress in medical training has been the subject of numerous investigations. ${ }^{8-10}$ Majority of medical students (73\%) perceived stress and stress among medical students is common and process oriented. ${ }^{11}$ In some studies, mean scores of stress were higher than those in other groups within the general population, and the estimated prevalence of emotional disturbance was $31.2 \%{ }^{12,13}$

A study done in Korea, medical students had a higher depression rate $(52.3 \%)$ than engineering students $(34.0 \%) .{ }^{14} \mathrm{An}$ Indian 
study among first year medical students, the incidence of anxiety was most prevalent. ${ }^{15}$ Higher levels of stress had also been reported in 1st year medical students in Karachi, Pakistan. ${ }^{16}$ Study from the United Kingdom showed, more than one third of first-year students had poor mental health when measured with the General Health Questionnaire 12, which assesses anxiety and depression. ${ }^{17}$ In Saudi Arabia, the prevalence of stress of all types among students of a medical college was found $57 \%$ and severe stress among $19.6 \%$ study subjects. The prevalence of stress was higher $(74.2 \%)$ in first year of study followed by second year $(69.8 \%) .{ }^{18}$

Anxiety and depression can be taken as reliable indicator for assessment of mental illness in a community. ${ }^{19}$ Information regarding related possible contributing factor of emotional status of recently admitted MBBS student can help necessary steps to prevent or treat any psychiatric morbidity like depression, anxiety and stress. Thus we can produce competent physicians who can face challenges of novel profession. The emotional status of students during medical school training has been a source of concern, reported as early as $1956 .{ }^{20}$ Globally different countries and Indian sub-continent published research works regarding depression, anxiety or stress among medical students. ${ }^{11,15,16,21,22}$ So far, similar study was not conducted in our country. This research was carried out with the objectives of assessing and quantifying the symptoms of depression, anxiety and stress among first year medical students in a public medical college,

\section{Materials and methods}

This was a descriptive cross sectional study conducted among 105 first year MBBS students (2009- 2010 academic session), of Khulna Medical College, Khulna, Bangladesh who were sampled purposively and satisfying inclusion and exclusion criteria in the period from December 2009 to July. Students with previously diagnosed cases of psychiatric illness or chronic debilitating physical illness were excluded from the study. Proper ethical procedures were maintained throughout the study.

Data were collected through face-to-face interview using semistructured questionnaire. Translated and validated Bangla version of the short-form version of the Depression Anxiety Stress Scales (DASS-21 BV) $)^{23}$ was applied. Original DASS-21 is a valid ${ }^{24}$ set of instrument having seven questions in English for each subscale. A sum of the scores in each of the sub-scales completed by each participant is evaluated as per the severityrating index. For short (21-item) version, multiplication of sum by 2 is needed. ${ }^{25}$ Pearson Bivariate correlation was used for qualitative variables/ ordinal scale to find any significant relation between independent and dependent variables. Chi-Square test was done to find any significant relation between categorical independent and dependent variables. Computer software DASS 21 scoring and interpretation generator provided by Clin Tools was used to obtained DASS $21 \mathrm{BV}$ interpretation and Statistical Package for Social Sciences, $17^{\text {th }}$ Version (SPSS-17) was used for statistical analysis.

\section{Results}

The results showed that, the age range of students was 17- 22 years. Most of them were within 18-19 years of age, mean (+SD) age of students was $18.80(+0.907)$ years and median 19 years with male predominance 57 (54.3\%) (Figure 1). In the sample, the ratio of male and female was 1.19:1. Majority of them were Muslims, remaining $16.2 \%$ were Hindus. 67 students $(63.8 \%)$ were from urban back ground. Most of them $(79 \%)$ were living in hostel. Almost all were unmarried (Table 1).

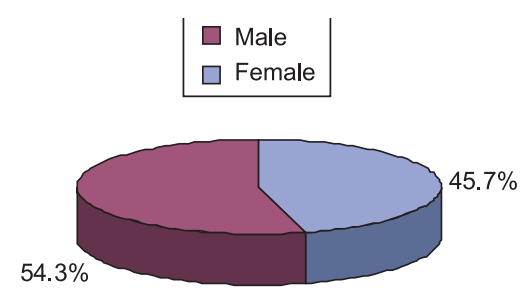

Figure 1: Sex distribution of the respondents $(n=105)$.

Table 1: socio-demographic characteristics of the respondents $(n=105)$

\begin{tabular}{llcc}
\hline Characteristics & & Frequency & Percent \\
\hline Habitat & rural & 37 & 35.6 \\
& urban & 67 & 64.4 \\
Present address & home & 22 & 21.0 \\
& hostel & 83 & 79.0 \\
Religion & Islam & 88 & 83.8 \\
& Hinduism & 17 & 16.2 \\
Marital status & unmarried & 103 & 98.1 \\
& married & 1 & 1.0 \\
& separated & 1 & 1.0 \\
\hline
\end{tabular}

Score in Depression subscale ranged 0-38, Mean (+SD) was 13.8 (+10.219), Median 10.0; Anxiety subscale ranged from 0-40, Mean (+SD) was $11.62(+8.806)$, Median 10.0 and Stress subscale ranged from 2-40, Mean (+SD) was 18.00 (+8.797), Median 16.0. Mean (+SD) of combined negative affect was 42.80 (+23.569), Median 36.0. Depression, anxiety and stress were found $54.3 \%, 64.8 \%$ and $59.0 \%$ respectively (Figure 2). 


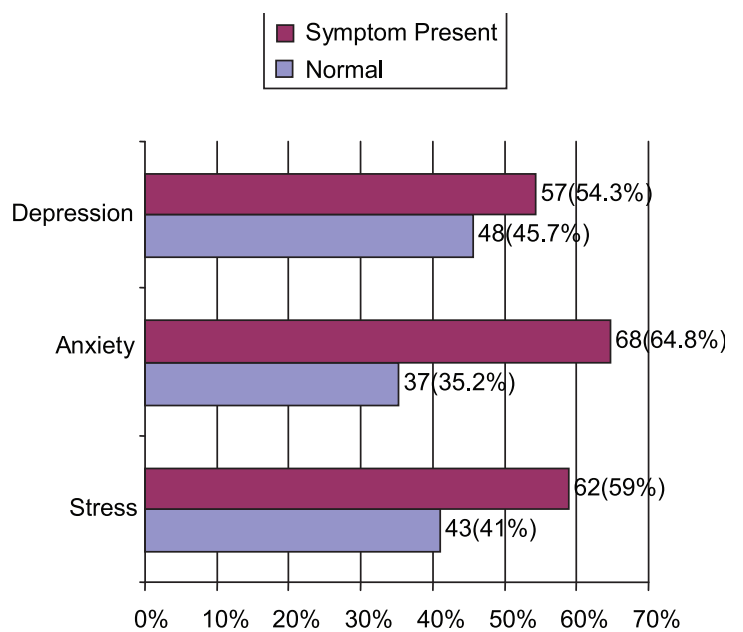

Figure 2: Depression, anxiety and stress among the students $(n=105)$

Moderate severity of symptom was predominant in all the subscale. Extremely severe symptom ranked second in depression and anxiety subscale, whereas severe symptom was second in stress subscale (Table 2). Combined interpretation of all 3 subscale showed that only $19.0 \%$ of students were symptom free, rest of them either had depression, anxiety or stress alone or combination of symptoms $(81 \%)$. Only depression was $6.7 \%$ whereas combination of depression, anxiety and stress was highest (36.2\%) (Figure 3 ). Age was positively correlated with depression (significant at $p<0.01$ level) and stress (highly significant at $p=0.001$ level) (Table 3).

Percentage of male and female suffering from depression was $52.6 \%$ and $56.3 \%$; anxiety was $66.7 \%$ and $62.5 \%$ and stress was $59.6 \%$ and $58.3 \%$. No significant association was found between gender difference and depression, anxiety or stress. No significant relation with other variables (habitat, present address, religion and marital status) and any of the DASS subscale (depression, anxiety and stress) were found (Table 4).

Table 2: Depression, anxiety and stress among students $(n=105)$

\begin{tabular}{|c|c|c|c|c|c|c|c|}
\hline \multirow[t]{2}{*}{ Severity of symptoms } & & \multicolumn{2}{|c|}{ Depression } & \multicolumn{2}{|c|}{ Anxiety } & \multicolumn{2}{|c|}{ Stress } \\
\hline & & Frequency & Percentage & Frequency & Percentage & Frequency & Percentage \\
\hline \multirow[t]{5}{*}{ Symptom present } & mild & 10 & 9.5 & 14 & 13.3 & 19 & 18.1 \\
\hline & moderate & 26 & 24.8 & 26 & 24.8 & 20 & 19.0 \\
\hline & sever & 6 & 5.7 & 9 & 8.6 & 18 & 17.1 \\
\hline & extremely sever & 15 & 14.3 & 19 & 18.1 & 5 & 4.8 \\
\hline & total & 57 & 54.3 & 68 & 64.8 & 62 & 59.0 \\
\hline
\end{tabular}

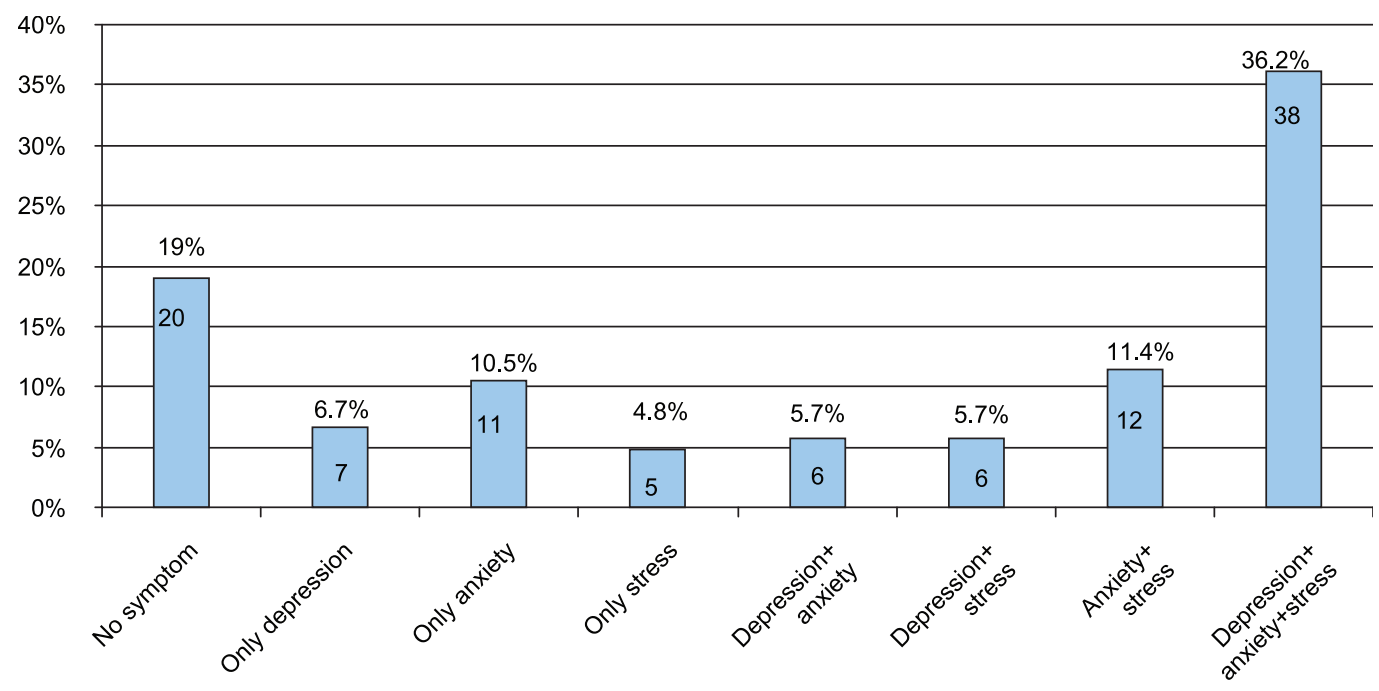

Figure 3: Interpretation of combination of 3 subscales (depression, anxiety \& stress) of DASS 21 BV ( $n=105)$ 
Table 3: Correlation between age and DASS subscales $(n=104)$

\begin{tabular}{ccccc}
\hline Age & DASS depression score & DASS Anxiety score & DASS Stress score & Combined negative affect \\
\hline $\mathrm{P}$ & $0.004^{* *}$ & 0.054 & $0.001^{* * *}$ & $0.001^{* *}$ \\
\hline
\end{tabular}

${ }^{* *}$ Correlation is significant, Pearson correlation was done

Table 4: Association between socio-demographic variables with depression, anxiety and stress $(n=105)$

\begin{tabular}{|c|c|c|c|c|c|c|c|c|c|}
\hline \multirow[t]{2}{*}{ Variables } & \multicolumn{3}{|c|}{ Depression } & \multicolumn{3}{|c|}{ Anxiety } & \multicolumn{3}{|c|}{ Stress } \\
\hline & $\begin{array}{c}\text { Frequency } \\
(\%)\end{array}$ & $\begin{array}{c}\chi^{2} \\
\text { value }\end{array}$ & $\mathrm{P}$ & $\begin{array}{c}\text { Frequency } \\
(\%)\end{array}$ & $\begin{array}{c}\chi^{2} \\
\text { value }\end{array}$ & $p$ & $\begin{array}{c}\text { Frequency } \\
\text { (\%) }\end{array}$ & $\begin{array}{c}\chi^{2} \\
\text { value }\end{array}$ & $p$ \\
\hline \multicolumn{10}{|l|}{ Gender } \\
\hline $\begin{array}{l}\text { male } \\
\text { female }\end{array}$ & $\begin{array}{l}30(52.6 \%) \\
27(56.3 \%)\end{array}$ & 0.137 & 0.711 & $\begin{array}{l}38(66.7 \%) \\
30(62.5 \%)\end{array}$ & 0.198 & 0.656 & $\begin{array}{l}34(59.6 \%) \\
28(58.3 \%)\end{array}$ & 0.019 & 0.891 \\
\hline $\begin{array}{l}\text { Habitat } \\
\text { rural } \\
\text { urban }\end{array}$ & $\begin{array}{l}23(62.2 \%) \\
34(50.7 \%)\end{array}$ & 1.254 & 0.263 & $\begin{array}{l}27(73.0 \%) \\
41(61.2 \%)\end{array}$ & 1.461 & 0.227 & $\begin{array}{l}24(64.9 \%) \\
38(56.7 \%)\end{array}$ & 0.657 & 0.417 \\
\hline $\begin{array}{l}\text { Present address } \\
\text { home } \\
\text { hostel }\end{array}$ & $\begin{array}{l}10(45.5 \%) \\
47(56.6 \%)\end{array}$ & 0.875 & 0.350 & $\begin{array}{l}15(68.2 \%) \\
53(63.9 \%)\end{array}$ & 0.143 & 0.706 & $\begin{array}{l}12(54.5 \%) \\
50(60.2 \%)\end{array}$ & 0.233 & 0.629 \\
\hline $\begin{array}{l}\text { Religion } \\
\text { Islam } \\
\text { Hinduism }\end{array}$ & $\begin{array}{c}48(54.5 \%) \\
9(52.9 \%)\end{array}$ & 0.015 & 0.903 & $\begin{array}{l}55(62.5 \%) \\
13(76.5 \%)\end{array}$ & 1.219 & 0.270 & $\begin{array}{c}54(61.4 \%) \\
8(47.1 \%)\end{array}$ & 1.206 & 0.272 \\
\hline $\begin{array}{l}\text { Marital status }{ }^{\dagger \dagger} \\
\text { unmarried } \\
\text { married } \\
\text { separated }\end{array}$ & $\begin{array}{c}55(53.4 \%) \\
1(100 \%) \\
1(100 \%)\end{array}$ & 1.717 & 0.424 & $\begin{array}{c}66(64.1 \%) \\
1(100 \%) \\
1(100 \%)\end{array}$ & 1.109 & 0.574 & $\begin{array}{c}60(58.3 \%) \\
1(100 \%) \\
1(100 \%)\end{array}$ & 1.414 & 0.493 \\
\hline
\end{tabular}

$* / * * * * *=$ significant; $\dagger \dagger=\mathrm{df} 2, \mathrm{df}$ of other variables is 1

$\chi^{2}$ value, $\mathrm{df}$ and $\mathrm{p}$ value reached from Chi-Square test

\section{Discussion}

The place of study is located in the city of Khulna, Khulna division; south-west region of Bangladesh. It is neither too old having complete structure and set up nor too new having very limited facilities like lack of academic infrastructures and inadequate manpower. So it would largely represent the overall condition of medical colleges of Bangladesh.

Bangla version of the short-form version of the Depression Anxiety Stress Scales (DASS-21 BV) was used instead of full version of DASS having 42 questionnaires. There are several published studies showing that the DASS 21 has the same factor structure and gives similar results to the full DASS. ${ }^{26}$ DASS 21 has the advantage of taking only half the time to administer. The items in the DASS21 were selected on the basis of several criteria like good factor loadings, coverage of all subscales within each scale and item means that, DASS21 scores for each scale should be very close to exactly half the full scale score. ${ }^{27}$ Bangla version was used in this study in place of original English version for better understanding of the respondents. The questionnaires were administered to the first year students after 1 month of orientation class. Within this time the classes were started in full swing with introduction of class tests called item examinations.

Moderate severity of symptom was predominant in all the subscale. Extremely severe symptom ranked second in depression and anxiety subscale, whereas severe symptom was second in stress subscale. Combined interpretation of all 3 subscale showed only $19.0 \%$ of students were symptom free, rest of them either had depression, anxiety or stress alone or combination of symptoms (81\%). Only depression was $6.7 \%$, anxiety was $10.5 \%$ and stress was $4.8 \%$; whereas combination of depression, anxiety and stress was highest (36.2\%). Percentage of male and female suffering from depression was $52.6 \%$ and $56.3 \%$; anxiety was $66.7 \%$ and $62.5 \%$ and stress was $59.6 \%$ and $58.3 \%$.

Though a study results brought into question the previously reported extent of chronic stress among students in the first year of medical school and strongly suggested that the first year medical school does not create an unusual amount of emotional distress in students, ${ }^{28}$ percentage of depression (54.3\%), anxiety ( $64.8 \%$ ) and stress ( $59 \%$ ) were high among 
medical students in KMC, Bangladesh. Nearly similar results were found in a study using DASS done in India where Depression 39.44\%, Anxiety $66.05 \%$ and Stress $51.37 \% .{ }^{15}$ While in Pakistan, prevalence of Anxiety and Depression among 1st year Medical Students of Private University was found $65.5 \% .{ }^{16}$ Stress level in another study in Pakistan was $66.3 \%$ among first year medical students. ${ }^{29}$ An author pointed out that, high level of Anxiety and Depression could be due to new study environment. ${ }^{16}$ In Saudi Arabia, the prevalence of stress among first year students of a medical College was also very high $(74.2 \%){ }^{18}$

A study result also indicated high percentage $(41.9 \%)$ of Malaysian medical students suffered from psychological stress and it was significantly associated with depression. ${ }^{30}$ However, the percentage of stress found in that study was lower than KMC students.

Among medical students of KMC, only $19 \%$ students were symptom free; remaining $81 \%$ either having only depression, anxiety or stress alone or in combination. Whereas a study done among the students of Dhaka University identified $55 \%$ of the first year students had clinical level of psychiatric distress. ${ }^{31}$ These differences might be due to more difficult academic curriculum and pressure of academic activity in medical college is more than other tertiary level of education.

In this study, age was positively correlated with depression and stress. In a study among the students of Dhaka University, significant association with age and psychiatric distress was found. ${ }^{31}$ But no correlation were found between depression and anxiety values and age in Turkey. ${ }^{32}$

Here no significant association was found with gender difference (male, female) and depression or anxiety or stress. Similar finding is seen in a study done in Dhaka University students where no significant association found between psychiatric distress and gender defference. ${ }^{30}$ This study results also have similarity with a study done in Portuguese where no significant difference was found between the stress level of male and female 1st year medical students ${ }^{33}$ and also in Malaysia. ${ }^{34}$ in the same way no significant gender differences for anxiety and depression was found in Pakistan. ${ }^{35}$ But an Egyptian study indicated that female students scored higher than males on depression scale while were similar on clinical anxiety and level of perceived stress. ${ }^{36}$ Studies among Swedish and Iranian medical students also showed female students suffering more from stress \& depression than male counterpart. ${ }^{37-38}$ In another Pakistani study, the female students reported significantly higher levels of perceived stress than their male counterparts and stressed cases were associated with being a female. ${ }^{29}$ In developing countries, women are more likely to experience depression than men. ${ }^{39}$ Other data from less developed countries sometimes found no gender difference in depression. ${ }^{40}$ The lack of a gender difference in this study may reflect the modernday changes in medical schools in this country. There are more female students entering medical schools. In recent years, number of female students in medical colleges is nearly equal to males. There has been an increase in women's participation in the work force and to some extent, in political life. Furthermore, globalization and exposure to Western culture have steered this traditionally Islamic country with alternative gender ideologies. In addition, lack of differences between the genders may be due to the highly selective and homogenous nature of the student population with unique personal characteristics desirable for the competitive environment of medical school. ${ }^{41}$ Moreover first year female students in this medical college were not involved in gender specific roll like child rearing and maintenance of family.

No significant association was found between any of the DASS subscale (depression, anxiety and stress) and rest of the sociodemographic variables of this study i.e. habitat (rural or urban), present address (living in home or hostel), marital status and religion. Though association was not significant in this study, students coming from rural areas suffered more than urban areas from depression (62.2\% and $50.7 \%)$, anxiety $(73.0 \%$ and $61.2 \%$ ) and stress (64.9\% and $56.7 \%)$. Likewise, among the university students from villages of Turkey had higher depression, anxiety and stress values than those from towns or cities. ${ }^{32}$ But significant association with origin (urban, rural) and psychiatric distress was found among Dhaka university students. ${ }^{31}$

In this study though students living at hostel suffering more from depression than home (56.6\% and $45.5 \%$ respectively), percentages regarding anxiety and stress are nearly equal. No significant association was found between any of the DASS subscale and present address (living in home or hostel). Similarly, no significant relation was found with stress and being away from home among Portuguese 1 st year medical students ${ }^{32}$ and psychiatric distress with living status (residential, non residential) of Dhaka university students. ${ }^{31}$ But Pakistani female medical students living in college dormitories were significantly more depressed and tendency to report anxiety more than those living at home. ${ }^{21}$

It is found that, equal percentage of Muslim and Hindu students were suffering from depression while more percentage of Hindu students suffering from anxiety and more proportion of Muslim students was suffering from stress. But no significant association was found between any of the DASS subscale (depression, anxiety and stress) and religion. Similarly religion did not contribute to stress among medical students of Malaysia. ${ }^{33}$ In the contrary, significant association was found with religion and psychiatric distress among Dhaka university students. ${ }^{31}$ 
In this study, only 1 female student was married and another male student was separated. Both of them had symptoms of depression, anxiety and stress. This size was too small to get any significant correlation. However, marriage appears to protect against distress ${ }^{5}$ and significantly lower depression scores among students who had an intimate partner as compared to those who did not have a partner. ${ }^{42}$ The result of the present study should be interpreted in light of the some limitations and caveats. Samples were taken from only one public medical college. There may have differences in socio-demographic characteristics, academic environment and other facilities between the students of different public and private medical colleges. Students of private medical colleges come from families of high socio economic status. So this sample size from only a medical college cannot represent all 1st year MBBS student of Bangladesh.

\section{Conclusion}

Steps should be taken to reduce depression, anxiety and stress among medical students. Adequate service should be provided to manage psychological problem by medical college authorityFurther research should be carried out on large sample in different medical colleges which should include both public and private medical colleges.

\section{References}

1. Folse ML, Darosa DA, Folse R. The relationship between stress and attitudes toward leisure among first-year medical students. J Med Edu 1985;60:610-7.

2. Eysenck NW. Anxiety, learning, and memory: a reconceptualization. J Res Personality 1979;13:363-85.

3. Liaison Committee on Medical Education. Functions and structure of a medical school: standards for accreditation of medical education programs leading to the MD degree. Washington DC: Liaison Committee on Medical Education; 2008. p. 5.

4. Association of American Medical Colleges. Report I Learning objectives for medical student education: guidelines for medical schools. Washington DC: Association of American Medical Colleges; 1998. p. 4-8.

5. Dyrbye LN, Thomas MR, Shanafelt TD. Medical student distress: causes, consequences and proposed solutions. Mayo Clin Proc 2005;80(12):1613-22.

6. Bunevicius A, Katkute A, Bunevicius R. Symptoms of anxiety and depression in medical students and in humanities students: relationship with big-five personality dimensions and vulnerability to stress. Int $J$ Soc Psychiatry 2008;54(6):494-501.

7. Saipanish R. Stress among medical students in a Thai medical school. Med Teacher 2003;25(5):502-6.

8. Ackerman TF, Wall HP. A programme for treating chemically dependent medical students. Med Educ 1994;28:40-6.

9. Deary IJ. Need medical education be stressful? Med Educ 1994;28:55-7.
10. Pasnau RO, Stoessel P. Mental health service for medical students. Med Educ 1994;28:33-9.

11. Supe AN. A study of stress in medical students at Seth G.S. Medical College. J Postgrad Med 1998;44(1):1-6.

12. Firth J. Levels and sources of stress in medical students. $\mathrm{Br}$ Med J 1986;292:1177-80.

13. Radcliffe $\mathrm{C}$, Lester $\mathrm{H}$. Perceived stress during undergraduate medical training: a qualitative study. Med Educ 2003;37(1):32-38.

14. Han SS, Lee SY, Choi WS, Kim SJ, Park SB, Lee SY. Depression and its influencing factors among Korean medical and engineering students in urban areas using zung self-rating depression scale. Korean J Fam Med 2009;30(7):539-48.

15. Vaidya PM, Mulgaonkar KP. Prevalence of depression anxiety \& stress in undergraduate medical students \& its co relation with their academic performance. IJOT 2007;39(1):7-10.

16. Inam SN, Saqib A, Alam E. Prevalence of anxiety and depression among medical students of private university. J Pak Med Assoc 2003;53(2):44-7.

17. Guthrie EA, Black D, Shaw CM, Hamilton J, Creed FH, Tomenson B. Embarking upon a medical career: psychological morbidity in first year medical students. Med Educ 1995;29:337-41.

18. Abdulghan HM. Stress and depression among medical students: A cross sectional study at a medical college in Saudi Arabia. Pak J Med Sci 2008;24(1):12-7.

19. Goldberg D. Identifying psychiatric illnesses among general medical patients. Br Med J 1985;291:161-2.

20. Saslow G. Psychiatric problems of medical students. J Med Edu 1956;31:27-33.

21. Rab F, Mamdou R, Nasir S. Rates of depression and anxiety among female medical students in Pakistan. East Mediterr Health J 2008;14(1):126-33.

22. Sreeramareddy CT, Shankar PR, Binu VS, Mukhopadhyay C, Ray B, Menezes RG. Psychological morbidity, sources of stress and coping strategies among undergraduate medical students of Nepal. BMC Med Educ [serial online] 2007Aug 2 [cited 2009 Nov 12]; 7:[26 screens]. Available from:URL: http://www.biomedcentral.com/1472-6920/7/26

23. Alim SMAHM, Kibria SME, Islam MJ, Uddin MZ, Nessa M, Wahab MA, et al. Translation of DASS 21 into Bangla and validation among medical students. Bang J Psychiatry 2014;28(2):67-70.

24. Henry JD, Crawford JR. The short-form version of the Depression Anxiety Stress Scales (DASS-21): Construct validity and normative data in a large non- clinical sample. Br J Clin Psychol 2005;44(2):227-39.

25. Gomez F. A Guide to the Depression, Anxiety and Stress Scale (DASS 21). Central and Eastern Sydney primary health networks. [Online]. [cited 2016 Sep 20]. Available from:URL:https://www.cesphn.org.au/images/ mental_health/Frequently_Used/Outcome_Tools/ Dass21.pdf 
26. Psychology Foundation of Australia. DASS publications. In: Depression Anxiety Stress Scales (DASS) [Online]. 2009 May 6 [cited 2009 Dec 24]. Available from:URL: http:// www2.psy.unsw.edu.au/groups/dass//pub.htm

27. Psychology Foundation of Australia. DASS FAQ (Frequently Asked Questions): Depression Anxiety Stress Scales (DASS). [Online]. 2014 Nov 10 [cited 2016 Sep 6]. Available from:URL: http://www2.psy.unsw.edu.au/dass/DASSFAQ.htm

28. Mitchell RE, Mathews JR, Grandy TG, Lupo JV. The question of stress among first year medical students. J Med Edu 1983;58:367-72.

29. Shah M, Hasan S, Malik S, Sreeramareddy CT. Perceived stress, sources and severity of stress among medical undergraduates in a Pakistani Medical School. BMC Med Educ [serial online] 2010 [cited 2010 May 25]; 10:2. Available from:URL: http://www.biomedcentral.com/1472$6920 / 10 / 2$

30. Sherina M, Rampal L, Kaneson N. Psychological stress among undergraduate medical students. Med J Malaysia 2004;59:143-5.

31. Sharmin N. Mental health problems among the students of Dhaka University and outcome of psychological treatment on them. Unpublished M. Phil thesis, Clinical Psychology Depertment, Dhaka University 2008 Sept.

32. Bayram N, Bilgel N; The prevalence and sociodemographic correlations of depression, anxiety and stress among a group of university students. Soc Psychiatry Psychiatr Epidemiol 2008;43(8):667-72.

33. Marques AF, Soares AR, Neves CF, Brilhante E, Tavares JF, Freitas JP et al. Stress levels in Portuguese 1st year medical students. [Online]. 2008 [cited 2010 May 25]. Available from:URL: medicina.med.up.pt/im/trabalhos07.../ INTROMEDII_Artigo_t21_Junho.doc
34. Yusoff MSB, Rahim AFA, Yaacob MJ. Prevalence and Sources of Stress among Universiti Sains Malaysia Medical Students. Malaysian J Med Sci 2010;17(1):30-7.

35. Khan MS, Mahmood S, Badshah A, Ali SU, Jamal Y. Prevalence of Depression, Anxiety and their associated factors among medical students in Karachi, Pakistan. J Pak Med Assoc 2006;56(12):583- 6.

36. Amr M, El Gilany AH, El-Hawary A. Does gender predict medical students' stress in Mansoura, Egypt? Med Educ [serial online] 2008 [cited 2008 Dec 25]; 13:12. Available from:URL: http://www.med-ed-online.org

37. Dahlin M, Joneborg N, Runeson B. Stress and depression among medical students: a cross-sectional study. Med Educ 2005;39(6):594-604.

38. Ahmadi J, Pridmore S, Fallahzadeh M. Neurotic scores in a sample of medical students. German J Psychiatry 2004;7:51-5

39. Burt VK. Women and depression: Special con-siderations in assessment and management. In: Lewis-Hall F, Williams TS, Panetta JA, Her-rera JM, editors. Psychiatric illness in women, Washington, DC: American Psychiatric Pub-lishing; 2002. p. 237.

40. Culbertson FM. Depression and gender: an in-ternational review. Am Psychol 1997;52:25-31.

41. Hojat M, Glaser K, Xu G, Veloski JJ, Christian EB. Gender comparisons of medical students' psychological profiles. Med Educ 1999;33:342-9.

42. Mikolajczyk RT, Maxwell AE, Naydenova V, Meier S, Ansari WE. Depressive symptoms and perceived burdens related to being a student: Survey in three European countries. Clin Pract Epidemol Ment Health [serial online] 2008 Jul 3 [cited 2009 Nov 21]; 4:19. Available from:URL: http:// www.biomedcentral.com/1745-0179-4-19 